\title{
Doping a source of Polymeric Waste Management
}

\author{
Uleanya Kelechi Ogochukwu \\ Department of Pure Chemistry, Faculty of Applied Sciences, National Open University of Nigeria, 14/16 \\ Ahmadu Bello Way, P.M.B. 80067 Victoria Island, Lagos, Nigeria.
}

\begin{abstract}
This work is being gingered by the rapidly increased menace of polymeric waste generated daily, their poor management and high industrial demand for conductive polymers. Five grams of the polymers: poly styrene, poly ethylene, poly propylene and nylon66 were doped with eight different concentrations of charcoal $(0.00 \%, 0.05 \%, 0.1 \%, 0.5 \%, 0.75 \%, 1.00 \%, 1.25 \%, 1.5 \%)$ under heat application and compressed in a wooden mould into tablets of the doped polymers. On testing for the electrical and thermal conductivity of the doped polymers, it was observed that its electrical conductivity and thermal conductivities was actually enhanced to measure up to the conductivity of some known semi conductors therefore can be employed in many industrial purposes like in the production of capacitors used in electronics on further refining.
\end{abstract}

Keywords: conductivity, charcoal, doping, polymers, wastes.

\section{Introduction}

Wastes are in various forms and types, and the existence, management and challenges in human settlements have been of concern to individuals, communities, governments, organizations, research and development ${ }^{1,2}$. It may be elegant to define waste as leftovers, excesses, surpluses, unwanted and remains that are discarded, castoff, rejected, superfluous, dumped and or thrown away. Although one thing is unique to all: they are unwanted materials, at a moment in time, which resulted from processes of production and or transformation of some material resources to another. Though, there are some schools of thought that believe that there is no material entity that is absolutely a waste. In this respect, it means such materials are only awaiting more purposeful uses and or there are not yet technologies of developing them into useful states and or entity $^{3,4}$. In other words, wastes are the remnants of productions, processing, non-serviceability, disuse and others that have been discarded and abandoned for wants of immediate use $\mathrm{s}^{3}$. Many scholars have worked and defined what constitutes wastes in human settlements, and in particular, the challenges posed in human settlements for sustainable development ${ }^{5,6,7}$. A marvel of polymer chemistry has it that plastics has become an indispensable part of our daily life. But its disposal causes environmental problems and poses health hazards, in addition to being a public nuisance. ${ }^{8}$ There is virtually no where plastics as mold, extrusions, grains and films are not used in reasonable quantities - in laboratories, homes, industries, schools and colleges, tourist centers and etc. ${ }^{9,2}$

Although polymeric wastes form over $90 \%$ of our daily family wastes in Nigeria, waste management has been a major challenge in the Nigerian society as well as in most African countries owing to the dual problem of increase in waste generation and the poor management of such ${ }^{10}$. The challenge however is not peculiar to Nigeria and Africa; in the US, studies showed that of the 30 million tons of plastic waste generated in 2009 that only 7\% was recovered for recycling. These plastic wastes end up in landfills, beaches, rivers and oceans and contributes to such devastating problems as the Great Pacific Ocean Garbage Patch, a swirling vortex of garbage, the size of a continent where plastic outnumbers plankton, assert ${ }^{9}$.

Polymers are large molecules composed of many repeated units, known as monomers. Due to broad range of properties, both synthetic and natural polymers play an essential and ubiquitous role in everyday life. Polymers are interessant materials: cheap, easy to be shaped, lightweight, non corrosive, strong (after stretching of polymeric chains, easy to functionalise, some of them can be cured in 3D-networks). Polymers depending on their physical properties may be classified as thermoplastic or thermosetting plastic materials. Thermoplastic materials can be formed into desired shapes under heat and pressure to become solids on cooling. If they are subjected to the same conditions of heat and pressure, and can be remoulded. Thermosetting materials once shaped cannot be softened or remoulded by the application of heat. The two major groups are the condensation and addition polymer but basically a polymer is a large molecule built up from numerous smaller molecules. These large molecules may be linear, slightly branched, or highly interconnected. In the latter case, the structure develops into a large three-dimensional network ${ }^{11}$. The smaller molecules used as basic building blocks for these large molecules are known as monomers. A good example is the commercially important material poly (vinyl chloride) made from the monomer vinyl Chloride ${ }^{12}$. 
Polymeric materials are disposed in Nigerian environment in the following forms:

Fig 1: Dumpsites in Onitsha municipal in Nigeria
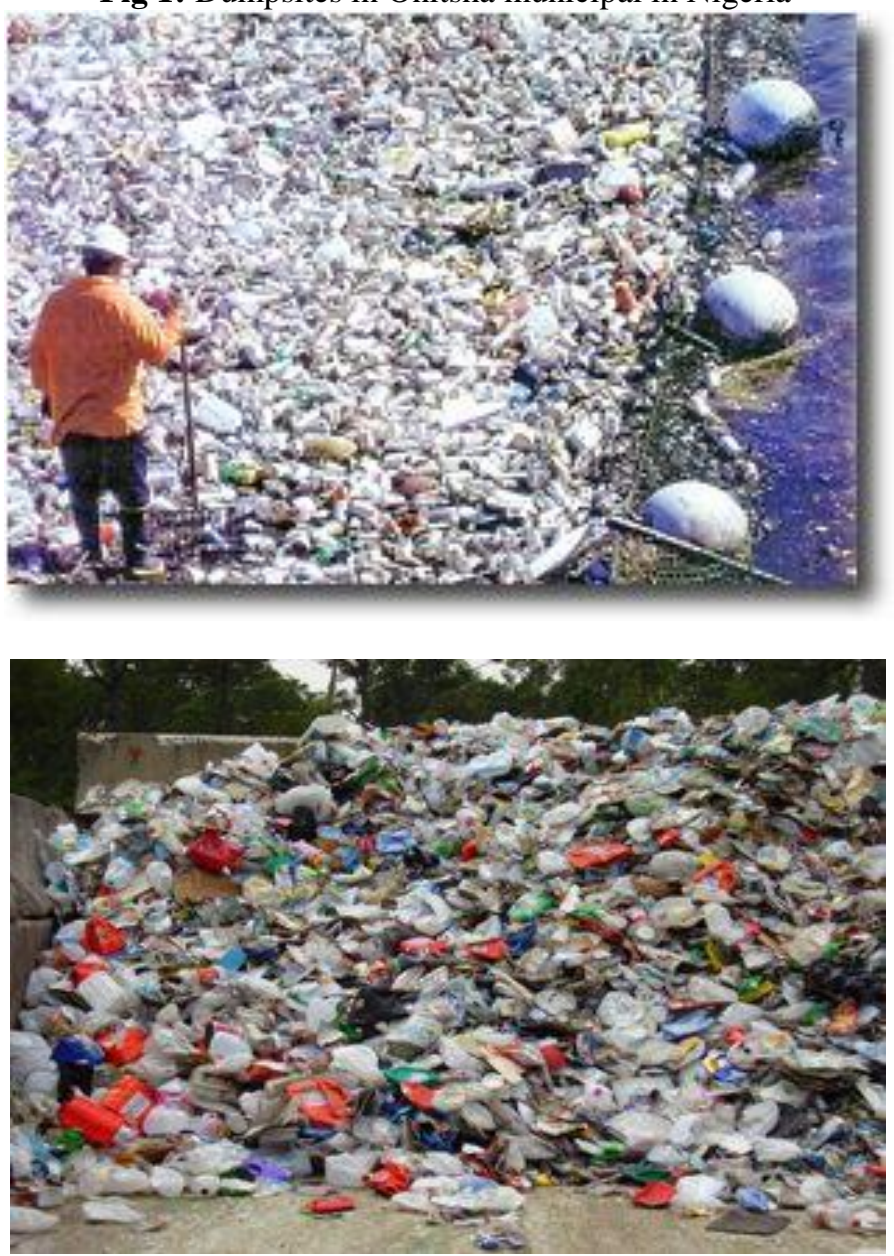

In view of the above information given on the overwhelming state of polymeric wastes, recycling of these wastes into useful products appears to be the solution. This work being gingered by the desire to contribute to salvaging our environment of this menace tried to dope this easily discarded polymeric wastes with wood charcoal to enhance their conductivity such that it can be employed for more stable industrial purposes since it is evidently clear that already made conductive polymers are not readily available and are of high cost efficiency. Most commercially produced organic polymers are electrical insulators. Conductive organic polymers often have extruded delocalized bonds often composed of aromatic units. When charge carriers from the addition or removal of electrons are introduced into the conduction or valence bands, the electrical conductivity increases dramatically. Technically almost all known conductive polymers are semi-conductors due to the band structure and low electronic mobility. However, the so called zero band gap conductive polymers may behave like metals. The most notable difference between conductive polymers and inorganic semi-conductors is the mobility, which until very recent was dramatically lower in conductive polymers than their inorganic counter parts though recent advancements in molecular self - assembly are closing that gap ${ }^{13}$. Metals are characterized by the presence of free electrons and can conduct electricity; non-metals have few or no electrons and cannot conduct electricity, while semiconductors are in between the two. Plastics are generally known as good electrical insulators ${ }^{14}$. Insulators break down for two reasons, firstly, the higher the voltage they must sustain, the greater the strain imposed upon their inter-atomic bonds and hence on their insulating properties. Every insulator has a voltage of a given thickness, beyond which it will break down and conduct either across its surface or throughout the bulk of the material. Secondly, the hotter the insulator, the greater the agitation within its crystal structure and the more likelihood there will be free electrons ${ }^{15}$. Conductive polymers are generally not thermoplastics i.e. they are not thermo formable although like insulating polymers they are organic materials. They have an advantage over other polymers because of their process ability which is mainly by dispersion ${ }^{16}$. The electrical properties of conductive polymers can be fine-tuned using the methods of organic synthesis ${ }^{17}$ and by advanced dispersion techniques ${ }^{18}$. The conductivity of polymers is the result of several processes. In the traditional polymers such as polyethylene, the valence electrons are bound in $\mathrm{sp}^{3}$ 
hybridized covalent bonds such sigma-bonding electrons have low mobility and do not contribute to the electrical conductivity of the material. Organic insulator decomposes at a temperature of a few hundred degrees centigrade, but ceramic insulators when very hot may conduct quite well. The more firmly restrained the electrons are in a material, the better its insulating properties.

At times, minute amounts of impurities or dopants may be introduced to an insulator to improve conductivity to desired amount and the process is known as doping ${ }^{19}$. These dopants or impurities either introduce mobile or free electrons into the insulator ${ }^{20}$. The conductivity of the doped material approaches the conductivity of the best available conductor, that is, silver. At room temperature, the conductivity of polyacetylene approaches the conductivity of copper on a weight basis and exists in cis-configuration at $195^{\circ} \mathrm{K}$ and trans- at room temperature ${ }^{17}$. However in conjugated materials the situation is completely different .Conducting polymers have backbone of contiguous $\mathrm{sp}^{2}$ hybridized carbon centres ${ }^{21}$. Conductive polymers are organic polymers that possess electrical, electronic, magnetic, and optical properties of a metal while retaining mechanical properties processibility commonly associated with a conventional polymer ${ }^{22}$. It can also be defined as any system that contains an additive to lower resistivity. The resistivity of unmodified polymers or plastics is $1016 \Omega \mathrm{m}$ while conductive additives can lower resistivity level in steps down to $104 \Omega \mathrm{m}$ resistivity range ${ }^{23}$. This work is focused primarily on the enhancement of their crucial properties: electrical and thermal conductivities which are required of a polymer for it to be accepted for all good uses especially as a semiconductor. Commonly discarded polymers and materials from the environment were used as a means of waste control. Cost management was considered since this has served as a strong limitation for their use. These desired polymers were achieved by doping with dopants to help lower the resistivity of the polymers thus increasing their conductivities. Therefore the doping process is the introduction of very small amounts of impurities example charcoal to generate charge carriers since concentrations of dopants causes certain electrons to become unpaired. Doping also leads to the formation of polarons and bipolarons which have extended porbital system that has more (n-type) or fewer (p-type) valence electrons to increase the conductivity of a semiconductor ${ }^{24}$.

\section{Materials And Methods}

All the materials and equipment used for this particular research were sourced from the chemistry and physics research laboratory of the Nnamdi Azikiwe University Awka, Cutix Cable Nnewi, Relief Market Onitsha and dust bin at electronic shops in Onitsha.

Materials: Non coloured sachet water bag used as polyethylene, non coloured rice bags used as poly propylene, white socks used as nylon66 and white brittle pack used for protecting electronic gadgets is used as polystyrene,. Charcoal was gotten from burnt wood.

Equipment: Electrical weighing balance from mettler Toledo 2007 mode serial no 021-64852350 ENGLAND, Stirring rods, Beakers (PYREX). Electro thermal Heater of about $250^{\circ} \mathrm{c}$ from Barnstaed 2006 model, serial no 10714483 England, Thermometer $-360^{\circ} \mathrm{C}$ thermometer, Wooden mould, Karthrometer, 500 mega ohms MASTECH multimeter No. 005-134.

Method: All polymeric wastes used were cut into tiny pieces, washed and sun dried. $5 \mathrm{~g}$ of each of the polymer were weighed into a $250 \mathrm{ml}$ beaker and heated at a regulated temperature of $130{ }^{\circ} \mathrm{C}-250{ }^{\circ} \mathrm{C}$ to melt it using a thermometer and on continuous stirring to maintain a uniform temperature. During the process care was taken not to allow degradation. The dopant of known different percentage concentrations $0.00,0.05,0.10,0.50,0.75$, $1.00,1.25,1.50$ was added into the beaker containing the polymer and the two mixed thoroughly while heating respectively. The mixture was then poured immediately into the mould and compressed to form a doped tablet of the polymers.

TABLE 1:Formulation of doped polymers

\begin{tabular}{|l|l|}
\hline Polymers $(\mathrm{g})$ & \% concentration of dopant \\
\cline { 2 - 2 } & Charcoal \\
\hline 5.00 & 0.00 \\
\hline 5.00 & 0.05 \\
\hline 5.00 & 0.10 \\
\hline 5.00 & 0.50 \\
\hline 5.00 & 0.75 \\
\hline 5.00 & 1.00 \\
\hline 5.00 & 1.25 \\
\hline 5.00 & 1.50 \\
\hline
\end{tabular}




\section{Characterization of the Sample}

(a) The electrical conductivity of the sample was carried out by using 500mega ohms MASTECH multimeter 005-1349. Each sample prepared was tested with the equipment by placing it between the two opposite rods of the multimeter and its resistance taken. Resistivity is the opposition given to flow of current per unit length of material of uniform sectional area and the reciprocal of resistivity was measured as:

$\mathrm{K}=\mathrm{I} / \mathrm{R}(1)$

Where $\mathrm{k}=$ Electrical conductivity

$\mathrm{R}=$ Resistance

(b) Thermal conductivity was carried out using Elmer 2AK kathrometer. The results were obtained from the equation below.

$\mathrm{q}=\mathrm{kdt} / \mathrm{dx}(2)$

Where $\mathrm{q}=$ heat flux $(\mathrm{w} / \mathrm{m} 2) \quad \mathrm{dt} / \mathrm{dx}=$ temperature gradient $(\mathrm{k} / \mathrm{m})^{16}$

\section{Results And Discussions}

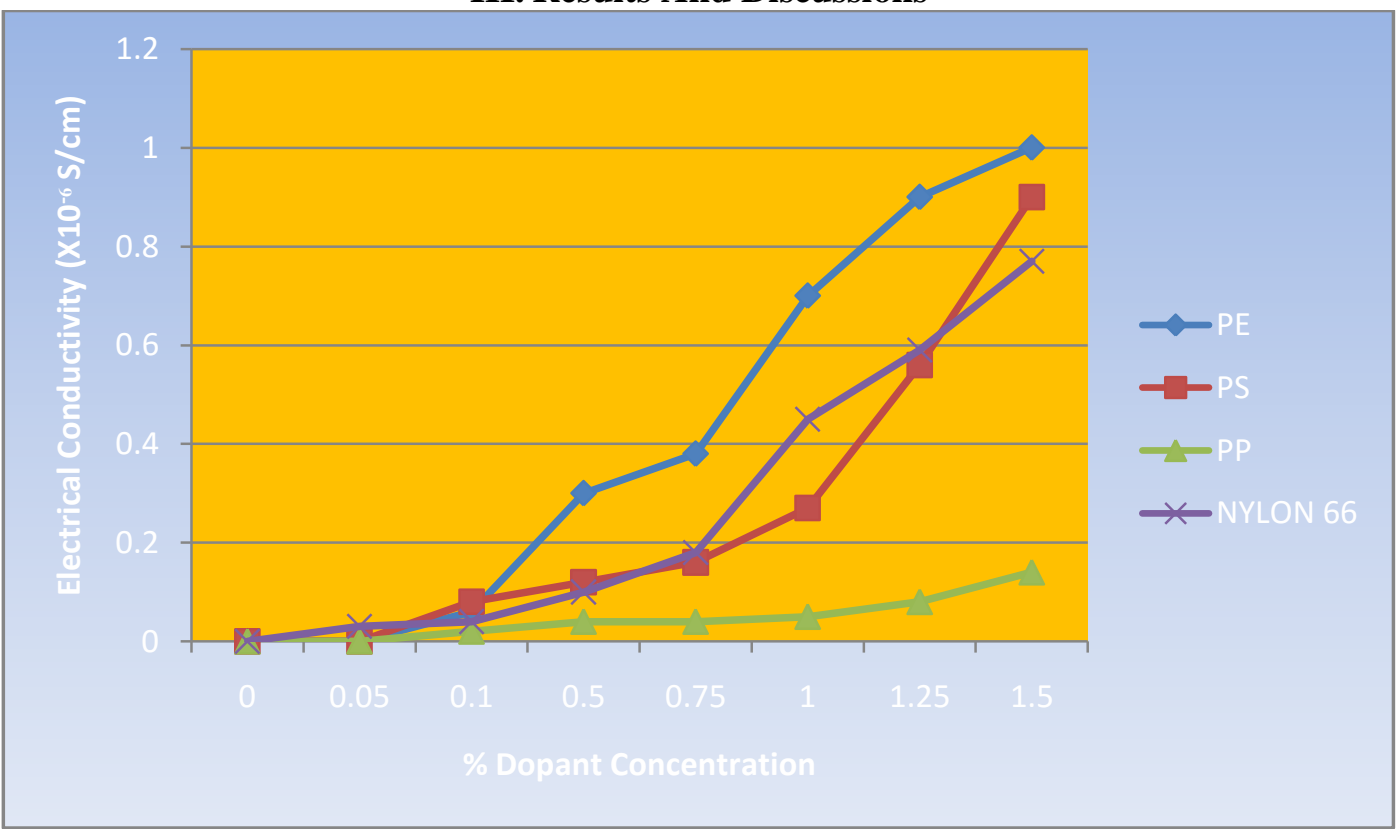

Fig ii: Effect of doping with charcoal on electrical conductivities of the polymers.

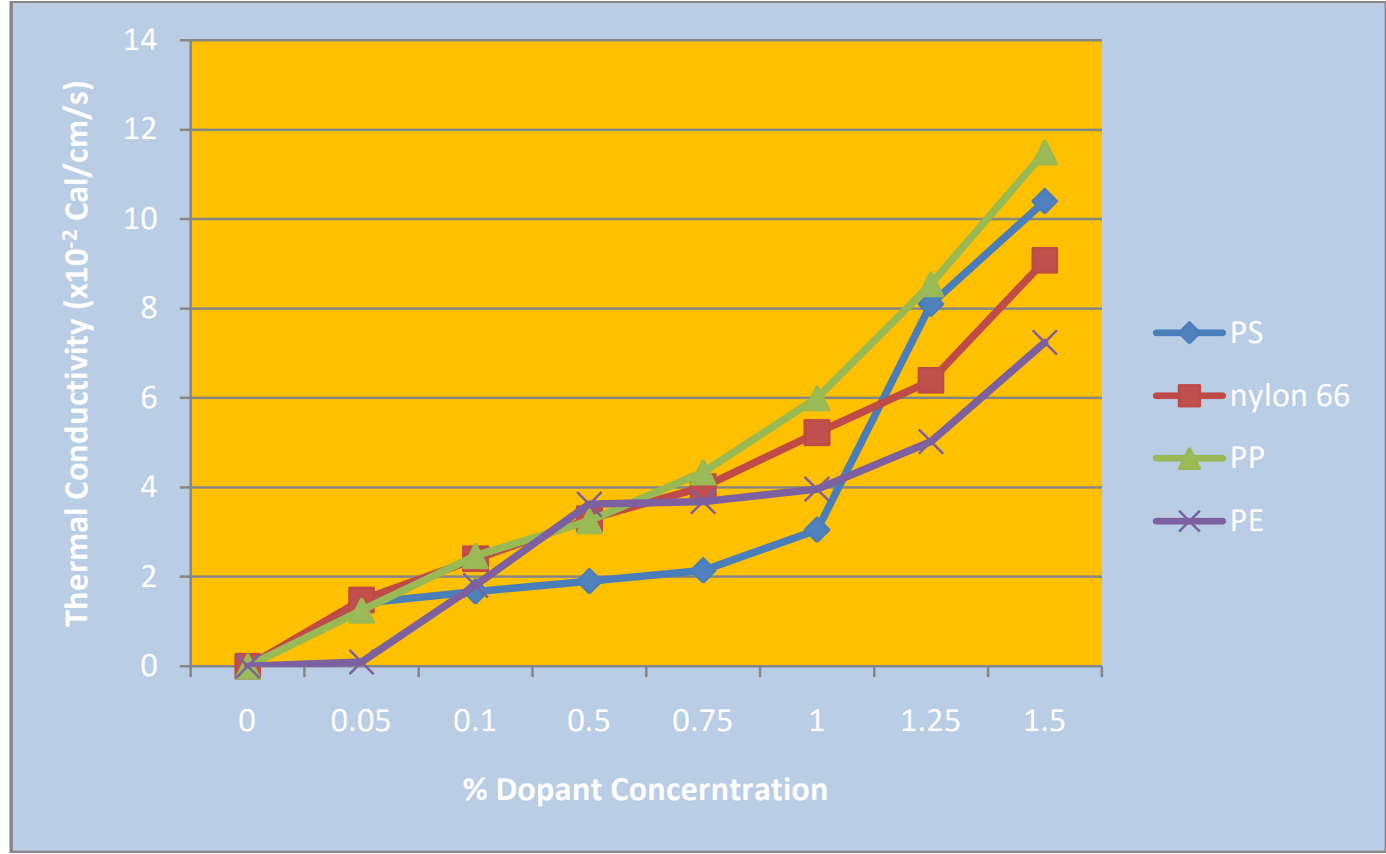

Fig iii: Effect of doping with charcoal on thermal conductivities of the polymers. 
It has been observed that the electrical resistance of metals is caused by the scattering of conducting electrons when they collide with ion cores during flow under a potential gradient, thus contributing to a heating effect. The displacement of the cores from their positions arises from their thermal motion. The thermal motion of the ion cores decreases with lowering of temperature with consequent lowering in the resistance character or increase in the conductivity level.

It has been observed that conductivity is increases by doping. Addition of charcoal increases conductivity of the different polymers at different degrees.

The conductivity of nylon66 normally an excellent insulator could be significantly increased by adding charcoal which has natural conductivity. The electrical conductivity of an organic polymer-poly acetylene could be increased by a factor of $10^{12} \mathrm{Scm}^{-1}$ when it was doped with an electron donor such as alkali-metal ion or an acceptor such as AsF5 or Iodine ${ }^{25}$. The conductivity of doped poly acetylene is comparable to that of copper on an equal weight bases. Addition of electron donors or acceptors causes doping that result in dramatic electronic and magnetic changes in the inherently conducting polymers along with increasing conductivity or approaching the metallic range. Doping is the oxidation or reduction of polymer molecules of poly cations or poly anions. Doping is reversible, removal of dopant or dedoping produces the original low conducting, semi conducting or insulating polymer usually without degradation of the polymer backbone.

Charcoal is amorphous in nature. Although it has similar layers as found in graphite it conducts electricity better because all the imprisoned electrons in the hexagonal carbon arrangement of the graphite molecules are free ${ }^{26}$ for movement in the amorphous charcoal. The conductive band of the carbons of the charcoal are brought closer to the valency band of the polymers for movements of electrons and holes. It is important to note the behaviour of nylon66 which improved significantly to compete with polystyrene PS could be explained by the amphorous charcoal which provides more available electron to add to those of the polar chain and thus significantly improving the electrical conductivity of the nylon 66 to meet the electrical conductivity of polystyrene (PS) which its behaviour is accounted for by the amorphous nature of the constituent hydrocarbon.

The most crystalline polymer polypropylene PP also exhibited the least electrical conductivity. There was also increased electrical conductivity with increasing concentration of dopants. This could also be explained by the increasing Island of charcoal in the polymer as the concentration of dopants increases ${ }^{27}$. This behaviour is more marked with amorphousness of the polymers thus this could explain why PS at higher concentration started to exhibit a better activity than nylon 66 that sort of competing with it at the lower concentrations.

PS performed best followed by PP in thermal conductivity. There was spiking which resulted from increased thermal conductivity at lower concentration. This which could be attributed to the increased organization or compactness provided by increased concentration of charcoal, which now increases heat transfer via phonon. It can be explained that the lower concentration spike is accounted for by electron movements while the higher concentration spike is accounted for by elastic wave like transfer of heats(photons) through the increased compact structure provided by the charcoal and direct transfer of energy from one atom to another.

\section{Conclusion}

The conjugated polymers in their undoped, pristine state are semiconductors/ insulators. As such the energy gap is around $2 \mathrm{eV}$ and higher and is too big for a considerable excitation of the charge carriers thermally. The undoped conjugated polymer, such as polythiophene, polyacetylene etc., has only a conductivity of around $10^{-10}$ to $10^{-8} \mathrm{~S} / \mathrm{cm}$. Upon doping the conjugated polymers there is a rapid increase of electrical conductivity of several orders of magnitude up to values of around $10^{-1} \mathrm{~S} / \mathrm{cm}$ even at a very low level of doping such as $<1 \%$. Subsequent doping of the conducting polymers will result in a saturation of the conductivity at values around $100-10000 \mathrm{~S} / \mathrm{cm}$ for different polymers. Thus from the results it is evidently clear that on doping, the polymers had both their electrical and thermal conductivities raised to that of some known semiconductors and its believed that on further saturation with dopants they can be employed in capacitors, optical diodes etc.

\section{References}

[1]. C.M Rochman.Plastics and priority pollutants: A Multiple Stressor in Aquatic Habitats. Environ. Sci. Technology.2013, 47(6):2439-2440.

[2]. K.D Klika. Waste plastics and pharmaceuticals, could an integration solution help? Environ. Sci. Technology.2013, 47(18):101-112

[3]. K.A Aderogba. Polymer wastes and management in cities and towns of Nigeria and sustainable environment ' Peak Journal of Physical and Environmental Science Research.2014 Vol.2 (1), pp. 1-12

[4]. G. Chen, M. Patel. Plastics derived from biological sources: Present and future: technical and environmental review. Chem. Rev.2014 112(4):2082-2099.

[5]. S. Beth (. Simple ways to reuse and recycle your holiday décor. London: World Street Journal (Saturday, 28 ${ }^{\text {th }}$ December 2012).

[6]. D. Evans , I. Bishop. Resource conservation and recycling. Oxford: Oxford University Press;2000 pp. $32,289-313$

[7]. R. Weber, C. Gaius, M. Tysklind, P. Johnston, M. Forter, H. Hollerti, E. Heinisch, I. Holoubeck, M. Lloyd-Smith, S. Masunaga, P. Moccarelli, D. Santillo, N.Seike, R. Symons, JP.Torres, M. Verta, G.Varbelow, J Vijqen, A.Watson, P. Costner, J Woelz, M. 
Zenneqq M. Dioxn- and POP- contaminated Sites - Contemporary and Future Relevance and Challenges: Overview and Background, Aims and Scope of the Series. Environ. Sci. Pollut. Res. Int. 2008 15(5):363-93.

[8]. The Hindu Tuesday, August 212001 online edition of India's National newspaper "Management of plastic wastes"

[9]. T. Ogwueleke. Municipal solid waste characteristics and management in Nigeria. Iran J. Environ. Health Sci. Eng.2006 6(3)173180.

[10]. J.O Akanmu. Integrated waste management: a tool for poverty alleviation. Proceedings of the National Engineering Conference and Annual General Meeting on Engineering Strategies for Poverty Alleviation. Abuja, (20 -24 November 2000), pp. 43-50.

[11]. K.J Saunder . Organic Polymer Chemistry: An Introduction to the Organic Chemistry of adhesives, fibers, paints, plastics, and rubbers. London: Chapman and Hall. (2 $2^{\text {nd }}$ Edition) 1998; pp. $6-11$.

[12]. J.W Nicholson.The Chemistry of Polymers. Cambridge: Royal Society of Chemistry. (4 ${ }^{\text {th }}$ Edition) $2012 ; \mathrm{pp} .14-23$.

[13]. N. Biodun . Conducting polymers,. Blackwell publishers London ${ }^{\text {rd }}$ Ed 1997 ISBN978 - 3674, pp 1-4.

[14]. G. Inzelt. Conducting polymers, A New Era in Electrochemistry Monographs ,Electrochemistry Springer ,2008, pp 265 - 267.

[15]. K.D Magic, V.E Pelitsky. Compendium of thermophysical Properties; Measurement Methods,. Plerium Press: New York, NY.1984 Vol.1 443 .

[16]. H. Naarman, Polymers Electrically conducting, (Ullman's Encyclopedia of Industrial Chemistry, 2000)

[17]. H.S Nalwa. Handbook of Nano structured and materials Nano Technology, Academic press .New york, NY USA.2000 Vol. 5, 501 $-575$

[18]. N.S Saricifici, Handbook of Organic Conductive Molecules and Polymers , World Scientific, Singapore, wiley \&sons Ltd Chichester 1994 vol.1-4

[19]. J. Brandup, E.H Immergnt. PolymerHandbook. 3rd Ed. Wiley- Interscience: New York, NY.1989 80.

[20]. P.S Parker. Concise Encyclopaedia of Science and Engineering, 3rd Ed. McGraw- Hill: New York, NY.1994 $456-457$.

[21]. L.T Brown, E.H Jr Lemay, E.B Brusten. Chemistry, The central science, modern materials $11^{\text {th }}$ ed.( Prentice-Hall Inc.) 2009

[22]. A.K Wanekaya, Y. Lei, E. Bekyarova, W. Chen, R. Haddon. Fabrication and properties of conducting polypyrrole, Electro analysis 18, No 11. ( wiley publishers wiley-VCH weinhem U.S.A., 2006) 1047-1054

[23]. S.J Dahman, Synthesis ,characterization and application of inherently conducting polymers, Journal of polymer engineering and science, 1999 vol. 39,11 .

[24]. R.K Monika. Synthesis of conducting polymers and their characterization, Indian Journal of Pure and Applied Physics.2010 vol.48, 524

[25]. S. Srilalitha, K.N Jayaveera, S.S Madhvendhra. "The effect of dopant , temperature and band gap on conductivity conducting polymers" International Journal of Innovative Research in Science ,Engineering and Technology,2013 vol.2, issue7, ISSN: 23198753.

[26]. R.B Seymour, T. Chery. History of poly olefins D. Reidd Dordrecht, The Netherlands.1986

[27]. S. Zaini. Municipal solid waste management in Malaysia. J. Appl. Sci. Environ. Sanit 2011. 6(1):29-38. 